\title{
Sustainability Issue in Tourism: A Case Study of Yuksam Village, Sikkim
}

\author{
Irengbam Rubita*
}

\begin{abstract}
North East India is blessed with abundant tourism resources, which are unique in their own way. The flora and fauna of this region is regarded as one of the seven most bio-diverse regions of the world. Among the States in this region, Sikkim is quite a popular destination with both the domestic and international tourists. It is perhaps the only state, where one can travel 3500 meters above the sea-level in a space of $160 \mathrm{~km}$. Sikkim is thus a trekker's paradise, offering a unique opportunity to trek to Mt. Kangchen-Dzonga. The gateway to this mountain is a small village called Yuksam in South Sikkim. Trends reveal that Yuksam is in the developmental stage of increasing growth of tourist influx, which would also have implications on the infrastructure, environment, natural resources, culture and eco-tourism of this village. So this paper aims to study how tourism in Sikkim, Yuksam in particular, can be sustained.
\end{abstract}

Keywords: Sustainable tourism, Homestay, KCC, Stakeholders, Yuksam, Bio-diversity

\section{Introduction}

Tourism is a vital engine of economic growth. Generating employment for 260 million and 10.7\% of the world GDP (UN WTO), today tourism industry is one of the fastest growing industries in the world. Tourism in India is also growing at a very

\footnotetext{
* Research and Teaching Assistant, IGNOU, School of Tourism and Hospitality Services Management- Block 1, IGNOU Maidan Garhi, New Delhi 110068; rubitairengbam@gmail.com
} 
fast pace and it is likely to become a global destination very soon. The tourism industry is one of the most profitable industries today. This is illustrated by the fact that in 2010, 5.58 million foreign tourists visited and spent Rs. 64,889 crores in India.

India's North East is blessed with abundant tourism resources, which are unique in their own way. The flora and fauna of this region is regarded as one of the seven most bio-diverse regions of the world. Recently, due to the lifting of PAP/RAP, there is a steady flow of tourists in this region, both domestic and international. Based on a recent report by Depa Laskar, the Regional Director of Union Ministry of Tourism, the North East of India has recorded the highest growth of tourism in India. The growth rate of foreign tourist arrival in the region in 2010-11 was 6.09 per cent, while in the domestic sector; the rate was 8.09 per cent. This is much higher compared to the all India rate which is only 7 per cent.

Tourism development in any area invariably leads to economic growth of that area, which manifests in terms of increase in income and employment opportunities, infrastructural growth, improvement in the standard of living etc. Its multiplier spin-off effects for the host communities are enormous, and have a wider distribution. But tourism development is often accompanied with a host of negative impact on ecology, environment and socioeconomic levels of the host communities' destination (Joshi \& Dhyani, 2009). This clearly indicates that there is an urgent need for advanced planning and management to control the tourism industry and more importantly to protect and conserve the biodiversity of the destination, not only by the policy makers but also the stakeholders and the local community as well. This is where sustainable tourism becomes important for the development of a destination.

\section{Review of Literature}

At the early stage of the present exercise, an attempt was made to highlight the ideas and views of eminent scholars in the fields of tourism and environment through a thorough review of the relevant literature. Social scientists, environmental analysts, 
tourism experts, sustainable development specialists and environment researchers have been attentive to the problems of their concerned areas over a period of time, reflecting their views, experiences and thoughts to overcome the challenges thrown by excessive tourism at the destination. From the vast array of published studies, the researcher has narrowed down on certain studies and selected the appropriate tool for analysis of the present research work.

Bressers (2004) while dealing with a theory of policy implementation for sustainable development strongly recommends motivation, information, and power as three core variables in understanding social interaction processes. The author also insists on developing an approach which will help us in knowing what works, where, when and how for successful sustainable development

Lafferty (2004) says that studying about environmental protection to sustainable development insists economic development should not affect the environment. Though, various models are adopted by various countries, none of them achieved Environmental Policy Integration. Finally, the author suggests that political commitment is very essential for achieving Sustainable Development

Sinclair and Stabler (1997) describe that the consumption of tourism product will be affected, due to social unrest at a particular destination and alteration in social context can bring in changes in the pattern of tourism consumption. Policies, if initiated by the government may help to alter the market structure, generating more positive output from tourism. Focused research, investigation of variables affecting tourism at a particular destination along with changes in motivation, preferences and expenditure pattern provide a clear view about tourism demand

Malhotra (1998) strongly favours cost effective methods for calculating tourism demand. Marketing strategies will be effective only when marketing plans are well understood and planned separately for each destination. When host community's feelings are generally ignored while formulating methods for tourism promotion, drastic impact on destination are observed, as a result 
of which local people lose interest in developing their destination further.

\section{Importance of the Study}

Tourism is a vital engine for economic growth, especially in the remote areas, and Sikkim is not exempted from this. Yuksum village, which is located in south Sikkim, is a remote area, where development of other industries is difficult owing to its nature. Tourism is the best option available for bringing in development in this area. Abundant natural beauty, flora and fauna have much potential to attract tourists in large numbers towards this region. Homestay is a concept introduced in these areas and local people are very much interested in this concept. Planned development with sustainable concept has to be followed right from the initial stages of developing the destination. For this purpose the present study is undertaken with the specific objectives.

\section{Objective of the Study}

1. To elucidate the status of tourism in the study area.

2. The opinion of local people and tourists regarding sustainable tourism development in the study area

3. To explore the scope of sustainable tourism in the study area.

4. To suggest further measure for development of sustainable tourism.

\section{Methodology}

The present paper is purely a qualitative analysis, based on the primary and secondary that is data available. Secondary data has been collected from the various available literatures like government reports, journals, existing policy of Sikkim and various other websites. The primary data such as the strength and weakness of the tourism product, is based on the selective personal interviews, using a structured questionnaire, conducted with the tourists, local people and Government Officials, working at the 
tourist site during my field work. Moreover an unobtrusive observation was also done by the researcher for a period of one month, during the study period to know more about the opinion of the local people and the domestic tourists.

\section{Sustainable Tourism}

The debates over the concept of sustainable tourism have been going on for a very long time. Figure 1 shows the chronological development of the concept of sustainable tourism.

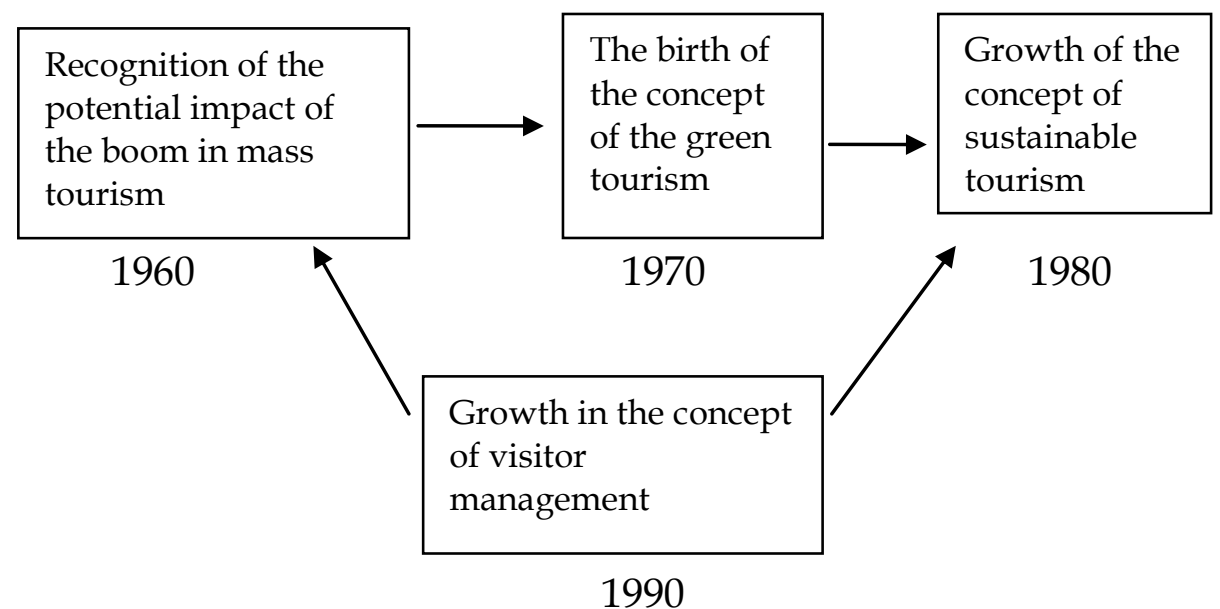

Fig.1: The Chronological Development of the Development of Sustainable Tourism

Source: Swarbrooke J, Sustainable Tourism Management, 2010

By sustainable tourism, we generally mean tourism which meets our needs today without compromising the ability of the people in the future to meet their needs. It is a kind of approach in tourism which makes development of tourism ecologically supportable in the long term. It motivates to conserve the resources and increase the value of local culture and tradition. There are many definitions for sustainable tourism. One of the most widely accepted one, is by the UN WTO. They define sustainable tourism as:

"Tourism which leads to management of all resources in such a way that economic, social and aesthetic need can be fulfilled while 
maintaining cultural integrity, essential ecological processes, and biological diversity and life support systems."

In addition to this, they describe the development of sustainable tourism as a process which meets the needs of present tourists and host communities, whilst protecting and enhancing their needs in the future (World Tourism Organisation 1996).

\section{Yuksam, Sikkim as a Tourism Destination}

The total area of Sikkim is approximately $40 \%$ of fixed land and another $30 \%$ of land is under snow capped mountains, glaciers \& rivers. Perhaps it is one of the rare places in the world, where one can travel from almost a level of 300 meters at Jorethang to 8598 meters above sea level at Khangchendzonga within a space of 110 $\mathrm{kms}$. This sharp variation in the altitude, naturally provides extremely rich bio-diversity in the State. However, what is striking as well as challenging to a tourist, is that the whole of Sikkim, except its capital Gangtok, is virtually virgin and unspoiled land, thus creating an aura of mystery around it.

Sikkim is thus a trekker's paradise, offering a unique opportunity to trek to Mt. Khangchendzonga. The gateway to this mountain is a small village called Yuksam in South Sikkim. Yuksam, which means "Meeting Place of the Three Learned Ones", was the first capital of Sikkim. It is a popular base for trekkers and nature lovers up to Dzongri (4030m), Goecha-La (5002m) near Mt. Khangchendzonga, the world's third highest mountain at $8586 \mathrm{~m}$.

Yuksam, lies on the edge of Khangchendzonga National Park, the largest protected area in Sikkim. Today, Yuksam still retains many of the attributes that earned the title of Ney-Pemathang, centuries ago. A hike in the nearby forest, offers a scene of exhilarating natural beauty and diversity. Deer, Bear, Civel Cat, Langur, Tehr, Goral, Red Panda, Mangoose, Pheasants, Magpies and Jungle Cocks can be found in the park.

Apart from being a biodiversity "Hot-Spot", Yuksam is a historically significant place of Sikkim. The first King of Sikkim 'Chogyal Phutsog Namgyal' was coroneted in Yuksam in the year 1642 AD. The stone throne shaded by a 300 year old fir tree still 
stands here today in Norbugang, as a historic cultural site maintained by the Archaeological Survey of India.

Kathok and Khecheopalri are the two important lakes of this area. Khecheopalri, known as the 'wishing lake' is one of the scared lakes of Sikkim. It attracts people from all over Sikkim during the festival held in February/March.

Dubdi Monastry is the oldest monastery of Sikkim. Located on the top of a hill, it is an hour walk from Yuksam. The walk to Dubdi through the lush forest high above the village is particularly rewarding for bird watchers.

Equally diverse are the cultures of the people of Yuksam, comprising of Bhutia, Lepcha and various Nepali ethnic people, practicing century old traditions. Some of the festivals celebrated here are Losar (Tibetan New Year), Naamsoong (New Year), Phang Lhabsol, Sagar Dawa (celebrating the triple blessed day of Buddha's Birth, Enlightenment and Death), Losoong (Harvest season), Dashain (Mark the victory of good over evil) etc. which attract a number of tourists to Yuksam.

\section{Importance of Tourism in Yuksam, Sikkim}

Sikkim is one of the most popular destinations of Northeast India, for both foreign and domestic tourists. The need for development of tourism is strategically much more important in Sikkim because of its geo-physical location; it is not possible to develop any heavy or medium industry in Sikkim. Only light industries which will not damage the fragile geo-physical and cultural environment will be suitable to a mountainous region like Sikkim. Thus, when there is a lack of any other industry, tourism is one of the most employment generating industries in Sikkim.

The below table shows that Sikkim received the maximum tourists both foreign and national, when compared to the other states of North East. 
Table 1: Tourists Arrival in North East, India

\begin{tabular}{|l|l|l|l|l|l|l|}
\hline \multirow{2}{*}{ State } & \multicolumn{2}{|c|}{2008} & \multicolumn{2}{c|}{2009} & \multicolumn{2}{c|}{$\begin{array}{c}\text { \% Growth } \\
\text { (2009/08) }\end{array}$} \\
\cline { 2 - 7 } & Domestic & Foreign & Domestic & Foreign & Domestic & Foreign \\
\hline $\begin{array}{l}\text { Arunachal } \\
\text { Pradesh }\end{array}$ & 149292 & 3020 & 195147 & 3945 & 30.7 & 30.6 \\
\hline Assam & 3617306 & 14426 & 3850521 & 14942 & 6.4 & 3.6 \\
\hline Manipur & 112151 & 354 & 124229 & 337 & 10.8 & -4.8 \\
\hline Meghalaya & 549936 & 4919 & 591398 & 4522 & 7.5 & -8.1 \\
\hline Mizoram & 55924 & 902 & 56651 & 513 & 1.3 & -43.1 \\
\hline Nagaland & 21129 & 1209 & 20953 & 1423 & -0.8 & -17.7 \\
\hline Sikkim & 460564 & 19154 & 547810 & 17730 & 18.9 & -7.4 \\
\hline Tripura & 245438 & 3577 & 317541 & 4246 & 29.4 & 18.7 \\
\hline
\end{tabular}

Source: Indian Tourism Statistics, 2009

This is also illustrated by the fact that, every year the tourists spent Rs. 20 crores in Sikkim.

Yuksam is in the developmental stage of increasing growth of tourist influx, which would also have implications on the infrastructure, environment, natural resources, culture and ecotourism of this village. Together with the area's heterogeneity in culture and tradition, rich bio-diversity, scenic beauty and historic religious place, Yuksam has become an attractive place for tourists. Over time, Yuksam has gained prominence as a fast developing tourist destination that the Indian Government has started promoting in this part of the country. As a result of this development, there is an increase in the number of tourists visiting this place, making the different impact of tourism very prominent.

The pressure on the resources increased, more infrastructure demand led to lessening of the surrounding forest, garbage and litter began to be a problem in the trekking trails and camp sites and different conflicts related with tourism began to be visible in Yuksam. Thus, there was an urgent need to develop sustainable tourism.

\section{Sustainable Tourism in Yuksam}

The diverse effect of tourism in Yuksam leads to growing concern amongst the local community to do something to lessen the various 
impacts of tourism and to conserve the resources that attract visitors to this area. The rules and guidelines set by the government and local authorities are not properly enforced. The local community and tourists was also not aware of how their action could impact the environment and their livelihood. And thus in 1996, Khangchenzonga Conservation Committee (KCC) was formed. KCC is a grass root, non-profit organisation, which works for the conservation of biodiversity in the Khangchenzonga National Park (KNP). It was formally registered with the Sikkim Government in 1997. One of the primary objectives of KCC is to promote eco-tourism in Sikkim Himalaya, so that the benefits of tourism, penetrate down to the community level and provide incentives for people to act for the conservation of their natural and cultural resources.

\section{The KCC and its Outcome}

Since its establishment in 1997, the KCC has accomplished a number of things in the short duration. Some of the works they have been doing are:

\section{Encourage homestay}

Yuksam being a small village, has a shortage of accommodation for the tourists. Physical plans are made for the development of tourism facilities and infrastructure, but the management plans are not prepared or followed. As a result, hotels are constructed but waste management is neglected. So, KCC started to promote homestay. This benefits both the local community and the tourists, as it allows cultural exchange. The local people also gain by having an alternate source of income. In return, tourists can participate in the cultural songs and dance, village walk and hike, ploughing the field, milking cow and making butter, cardamom weeding and harvesting, bird and butterfly watching, preparing local food and beverage etc. This not only helps in earning an extra income for the local community, but also somehow helps in checking waste management. 


\section{Code of conduct for homestay}

KCC plans a kind of a Code of Conduct for homestay, for both local people and tourists. They organise awareness camps for this, so that the local people become more aware of both the negative and positive impacts of tourism. Some Code of Conduct is:

- Always travel with a guide

- Be sensitive towards the cultural values of the local community,

- Dress modestly

- Avoid littering

- Dispose garbage at the designated place etc.

\section{Providing training to its community stakeholders}

Yuksam earlier hired trekking guides from neighbouring towns like Gangtok, Darjeeling and even from Nepal. This resulted in the leakage of income. To counteract this, KCC trains local guides and porters. They are not only given training for the skills, but they are also made aware of environmental issues. They are made aware that, if the natural flora and fauna are not preserved, the surrounding area will lose its beauty and charm. This training has not only helped provide alternate livelihood and sustain the income to the local people from tourism, but also have to some extent helped in sustaining the environment.

\section{Increase stock of kerosene supply for tourists}

Trekkers during the trekking have to use kerosene for cooking. But due to the low supply of kerosene, they have no choice but to use firewood. Earlier, the supply of kerosene was 10 barrels, but they made request to the Food and Civil Supplies Departments to increase the barrels to 20. This step ensures that trees are not cut to be used as firewood. They have also made a Code of Conduct to not use firewood within KNP.

\section{Garbage management within KNP}

Non-biodegradable garbage was a main problem, especially around the camp site and trekking trail. It pollutes the natural and 
cultural purity of the area. KCC makes a Code of Conduct which was given legal backing. So, before going to trek, nonbiodegradable items like food packages, bottles etc. are counted at the check post. While coming back, they have to bring back the same, which they have listed before going. This garbage is segregated at the check-post and recycled and others are disposed off in an environmentally clean way. Also, the garbage dumped for the past thirty years are brought back and disposed off.

So far, KCC has been successful in implementing all these within Yuksam. Now, KCC is planning to increase local participation in conservation activities and issues, especially of women, children and the younger generation. They will be arranging training programmes to improve the skills of potters, guides, cooks etc. They will also work to strengthen the relation between the government agencies, such as the forest and rural developments and NGO/INGO's to assist and enhance conservation development.

\section{Suggestions}

The measures taken up by the Khanchenzonga Conservation Committee (KCC) have so far helped in maintaining the bio diverse 'Hit-Spot' Yuksam, and is a success story not only in the whole of Sikkim but at the National level as well. This model of KCC can be adopted by other parts of Sikkim as well. Some suggestions to improve this are:

\section{Improvement of facilities}

While interviewing the tourist, they lament the lack of some basic facilities in and around the trekking area and the camping site. For e.g., the local huts situated at Goechala trek, should be restored and maintained. The hut should be made comfortable by making some arrangements to warm up the place. Basic furniture like a bed, chair and table can be placed.

\section{Single window system}

There are too many permits needed to visit Khanchenzonga National Park (KNP), which have to be obtained from Gangtok, resulting in losing out precious time on the part of the tourists due 
to lack of information on the part of the tourists as well as the travel agents. So, a single window system can be set up in Yuksam, where tourists can get all the necessary documents and permits.

\section{Promote niche tourism}

Mass tourism should be avoided. Being an area with a fragile ecosystem, tourism planners should only promote niche marketing for this area.

\section{Awareness programme}

Not only the local people but government, non-governmental organisations, industries, people relating not only to tourism but also tourists (before, during and after the trip) should be involved in education/awareness about sustainable tourism. Tourism planners should seek to increase people's involvement and ownership of tourism at the end of their destination.

\section{Development of environmental regulation}

Environment Impact assessment (EIA) should be introduced prior to the development of large scale projects like hotels. Not only EIA but carrying capacity calculations like physical carrying capacity, social carrying capacity, real carrying capacity etc. should be initiated by the Government from time to time to check the impact on the environment.

\section{Conclusion}

The next generation of travellers will be even more demanding regarding issues like sustainability, since they also feel the pressure for change. "The evidence indicate that tourists are not specifically demanding the so-called 'green' or 'eco labels' on the product that they select, but they will not return to destination which fails to offer environmental quality as a part of tourism experience" (Middleton and Hawkin, 1998). Therefore we need to prepare, so that we can respond to these kinds of demands. 


\section{Scope for further research}

The research was done using both the primary and secondary data collected during October 2010, which is a peak season for domestic tourism in the area of the study. Further, studies can be conducted on similar lines for foreign tourists also. Homestay has just started and the concept is slowly picking up the interest of the local people. Further, studies can be conducted after a gap of few tourist seasons. The study area is limited to Yuksum village in South Sikkim; further studies can be arranged in larger areas as the tourism policy is designed for the entire state and it is common.

\section{References}

Bressers, H. T. A. (2004). Implementing sustainable development: How to know what works, where, when and how, In William M. Lafferty, (Ed.), Governance for sustainable Development the Challenge of adopting form to function, Edward Elgar, Northampton MA, 284 - 318.

Joshi, R., \& Dhyani, P. P., (2009). Environmental sustainability and tourism-implications of trend synergies of tourism in Sikkim Himalaya, Current Science, 97(1), 33-41.

Lafferty, W. M. (2004). From environmental protection to sustainable development: $\mathrm{He}$ challenge of decoupling through sectoral integration, 191 - 220, In William M. Lafferty, (Ed.), Governance for sustainable Development The Challenge of adopting form to function, Edward Elgar, Northampton MA.

Malhotra, R. K. (1998). Tourism marketing, New Delhi: Anmol Publication.

Sinclair, M. T., \& Stabler, M. (1997). The economics of tourism. London: Routledge.

Swarbrooke., J. (2010). Sustainable tourism management. Jaipur: Rawat Publication. 